\title{
Chemical characterisation of water-soluble ions in atmospheric particulate matter on the east coast of Peninsular Malaysia
}

\section{Naomi J. Farren et al.}

Correspondence to: Jacqueline F. Hamilton (jacqui.hamilton@york.ac.uk)

The copyright of individual parts of the supplement might differ from the CC BY 4.0 License. 
Table S1: Recovery levels of the extracted target ions and associated $\% \operatorname{RSD}_{\text {rec }}(\mathrm{n}=3)$. Procedural blank peak areas for each ion and average blank contribution to field samples over the entire sampling period are also shown.

\begin{tabular}{|c|c|c|c|c|}
\hline Ion & \% Recovery & $\% \mathbf{R S D}_{r e c}(\mathbf{n}=\mathbf{3})$ & Blank area / $\mu \mathrm{S}$ min $^{-1}$ & Average $\%$ blank contribution \\
\hline $\mathrm{Cl}^{-}$ & 79.5 & 2.9 & $3.31 \times 10^{-3}$ & 2.7 \\
\hline $\mathrm{NO}_{2}^{-}$ & 81.5 & 3.2 & not detected & not detected \\
\hline $\mathrm{NO}_{3}^{-}$ & 78.8 & 5.3 & $6.19 \times 10^{-3}$ & 7.6 \\
\hline $\mathrm{PO}_{4}^{3-}$ & 98.2 & 5.6 & $2.38 \times 10^{-2}$ & 52.0 \\
\hline $\mathrm{SO}_{4}^{2-}$ & 80.4 & 7.9 & $1.31 \times 10^{-2}$ & 1.0 \\
\hline $\mathrm{CH}_{3} \mathrm{SO}_{3}^{-}$ & 74.5 & 2.8 & not detected & not detected \\
\hline $\mathrm{C}_{2} \mathrm{O}_{4}^{2-}$ & 82.5 & 2.9 & not detected & not detected \\
\hline $\mathrm{Na}^{+}$ & 87.3 & 6.0 & $6.51 \times 10^{-1}$ & 53.8 \\
\hline $\mathrm{NH}_{4}^{+}$ & 80.0 & 4.6 & $2.03 \times 10^{-2}$ & 4.9 \\
\hline $\mathrm{K}^{+}$ & 78.3 & 5.3 & $1.31 \times 10^{-2}$ & 12.5 \\
\hline $\mathrm{Mg}^{2+}$ & 83.3 & 4.8 & $3.76 \times 10^{-2}$ & 26.1 \\
\hline $\mathrm{Ca}^{2+}$ & 123.3 & 7.6 & $5.21 \times 10^{-2}$ & 34.0 \\
\hline
\end{tabular}


Table S2: Instrumental parameters and associated errors for the IC.

\begin{tabular}{|c|c|c|c|c|c|}
\hline Ion & RT range / min & LOD / ng & LOQ / ng & $\% \operatorname{RSD}_{\text {ins }}(\mathrm{n}=10)$ & $\% \mathbf{R S D}_{\text {total }}$ \\
\hline $\mathrm{Cl}^{-}$ & $4.97-5.00$ & 9.61 & 46.01 & 7.97 & 11.2 \\
\hline $\mathrm{NO}_{2}^{-}$ & $5.86-5.89$ & 5.47 & 25.25 & 22.36 & 6.38 \\
\hline $\mathrm{NO}_{3}^{-}$ & $8.16-8.31$ & 8.70 & 36.18 & 13.31 & 6.88 \\
\hline $\mathrm{PO}_{4}^{3-}$ & $11.23-11.38$ & 13.96 & 42.91 & 14.40 & 8.49 \\
\hline $\mathrm{SO}_{4}{ }^{2-}$ & $13.61-13.70$ & 20.98 & 66.46 & 8.02 & 22.6 \\
\hline $\mathrm{CH}_{3} \mathrm{SO}_{3}^{-}$ & $4.50-4.53$ & 6.16 & 29.47 & 10.26 & 13.9 \\
\hline $\mathrm{C}_{2} \mathrm{O}_{4}^{2-}$ & $15.72-15.85$ & 9.99 & 144.18 & 13.58 & 15.4 \\
\hline $\mathrm{Na}^{+}$ & $4.10-4.14$ & 1.01 & 2.51 & 3.32 & 6.35 \\
\hline $\mathrm{NH}_{4}^{+}$ & $4.64-4.68$ & 0.77 & 2.96 & 4.38 & 9.26 \\
\hline $\mathrm{K}^{+}$ & $5.71-5.77$ & 1.65 & 2.79 & 3.55 & 6.72 \\
\hline $\mathrm{Mg}^{2+}$ & $8.84-9.06$ & 2.11 & 3.67 & 4.73 & 10.6 \\
\hline $\mathrm{Ca}^{2+}$ & $10.99-11.28$ & 0.47 & 6.14 & 5.32 & 14.3 \\
\hline
\end{tabular}




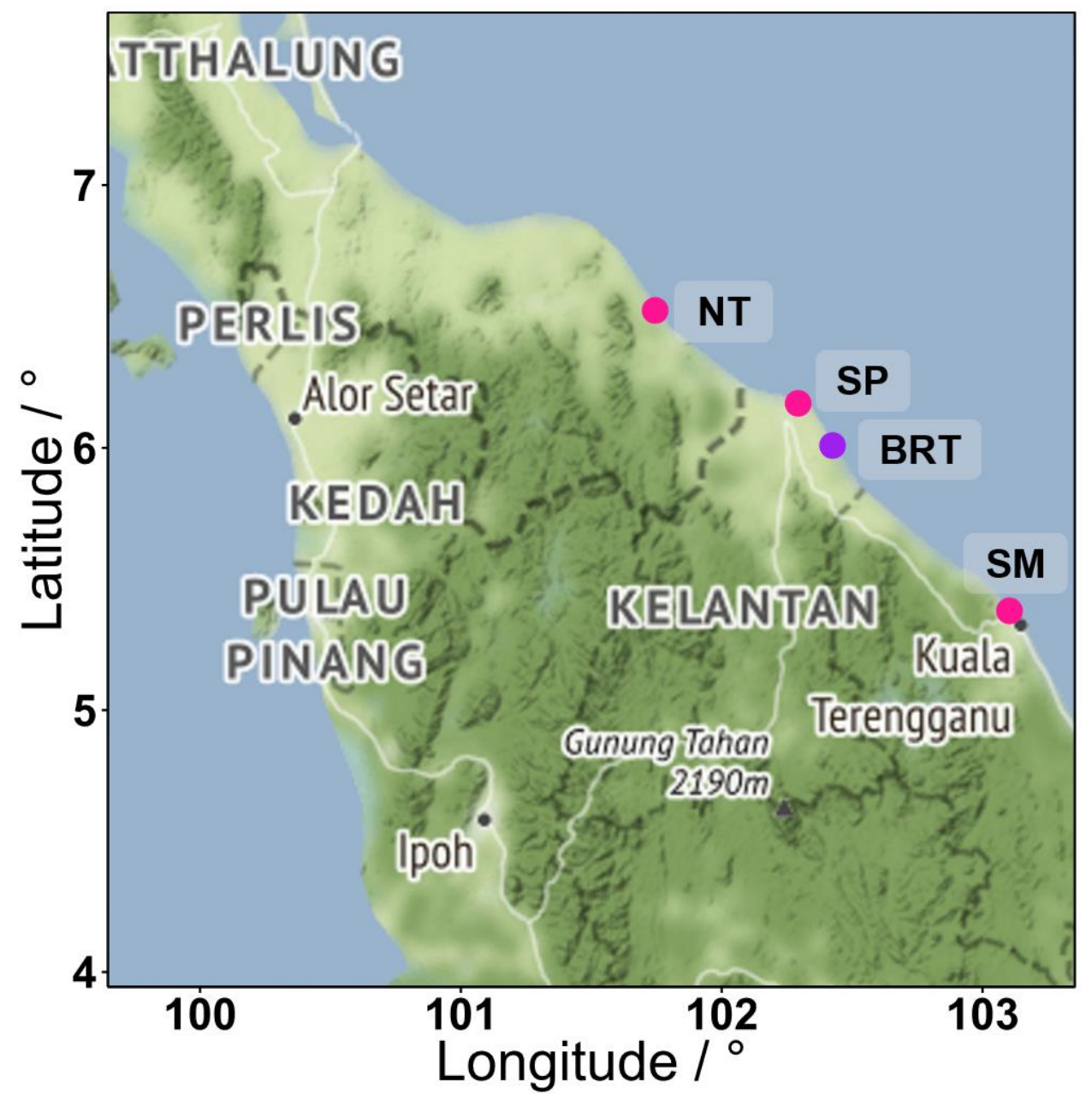

Figure S1: Map to show the Bachok research station (BRT) and the locations of three nearby meteorological stations: Narathiwat airport (NT), Sultan Ismail Petra airport (SP) and Sultan Mahmud airport (SM). 


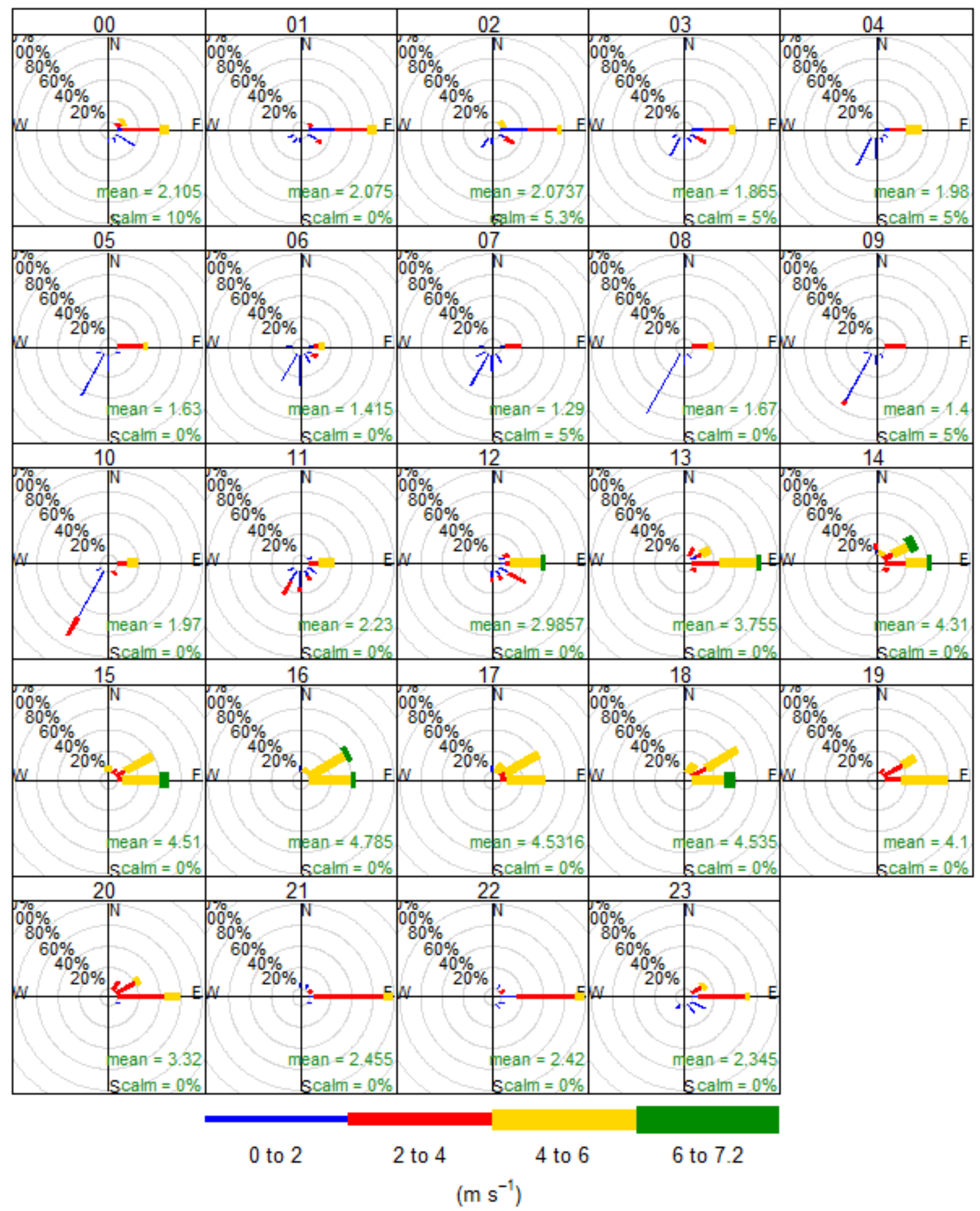

Frequency of counts by wind direction (\%)

Figure S2: Wind rose plots to show hourly wind speed and wind direction averaged across the measurement campaign (18-01-2014 to 06-02-2014). Plot constructed using the openair package in RStudio (Carslaw and Ropkins, 2012; Carslaw, 2015). 

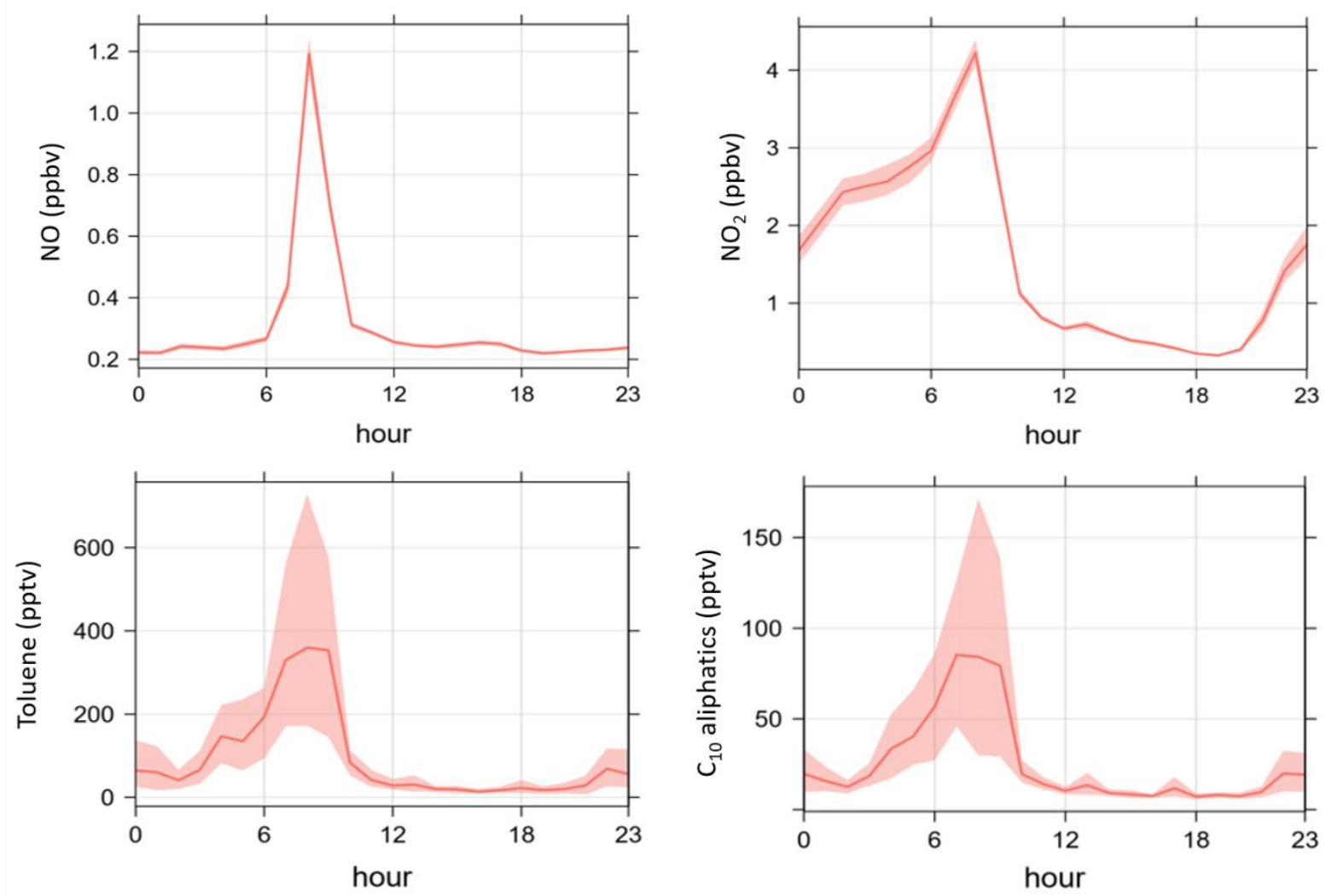

Figure S3: Diurnal profiles of NO, $\mathrm{NO}_{2}$, toluene and $\mathrm{C}_{10}$ aliphatics measured using GC-GC $\times \mathrm{GC}$ (Dunmore et al., 2016). The solid line represents the mean daily concentration and the shaded regions show the $95 \%$ confidence intervals surrounding the mean. Plot constructed using the openair package in RStudio (Carslaw and Ropkins, 2012; Carslaw, 2015).

Table S3: Average altitude, pressure and $\mathrm{SO}_{4}{ }^{2-}$ concentration of air masses arriving at the Bachok measurement site within each cluster.

\begin{tabular}{cccc}
\hline Cluster & Mean altitude (m) & Mean pressure (mbar) & Mean $\mathbf{S O}_{\mathbf{4}^{2-}}\left(\boldsymbol{\mu g} \mathbf{~ m}^{-\mathbf{3}}\right)$ \\
\hline 1 & 72 & 989 & 14.4 \\
2 & 169 & 991 & 8.4 \\
3 & 501 & 944 & 13.8 \\
4 & 37 & 1003 & 8.3 \\
5 & 1027 & 895 & 18.1 \\
\hline
\end{tabular}




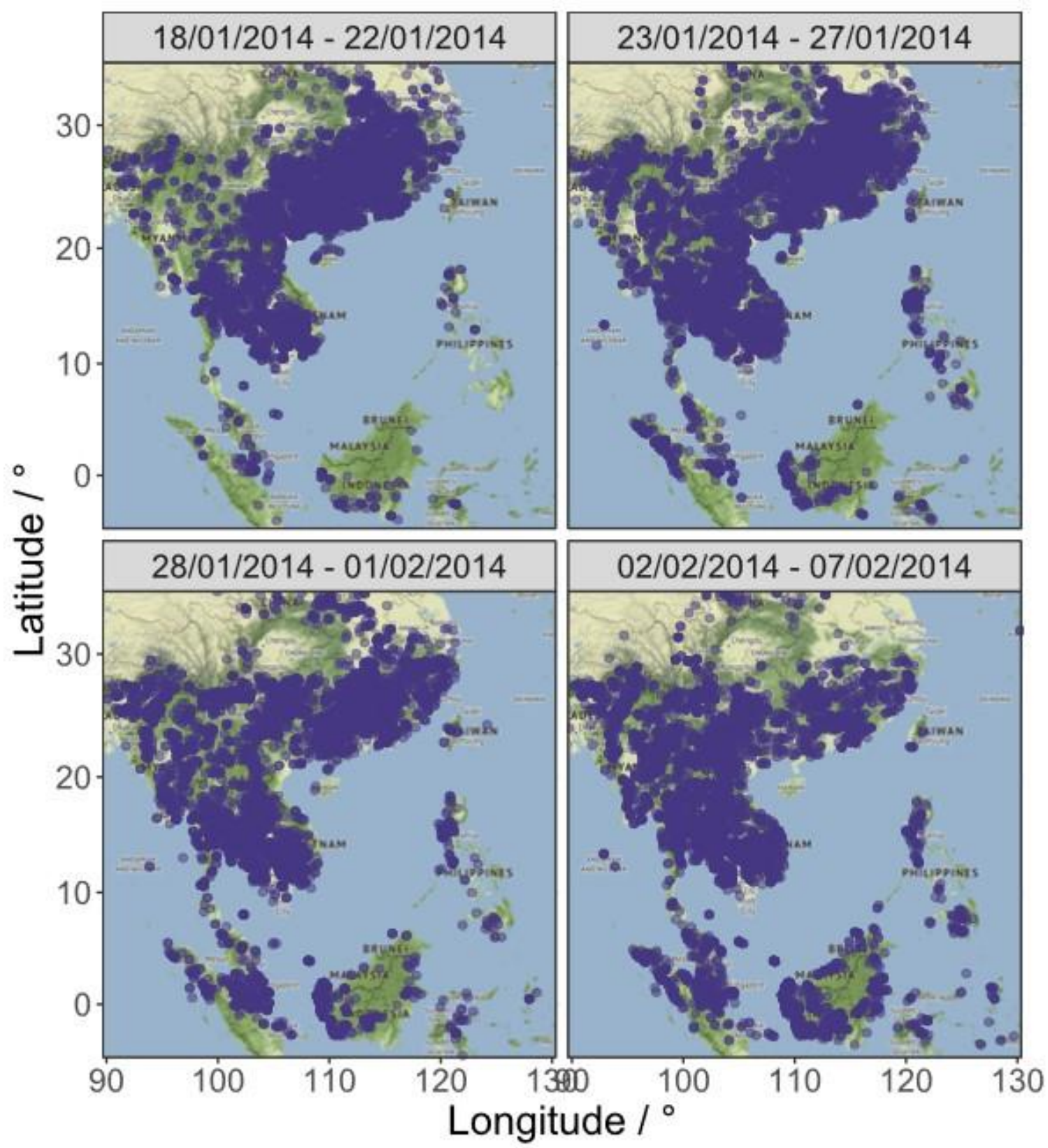

Figure S4: Fire maps for the duration of the Bachok measurement period. Data obtained from the moderate-resolution imaging spectroradiometer (MODIS) instrument on board the NASA Terra satellite (Giglio et al., 2003). Fire maps accessed via the global forest watch website (GFW, 2018). 


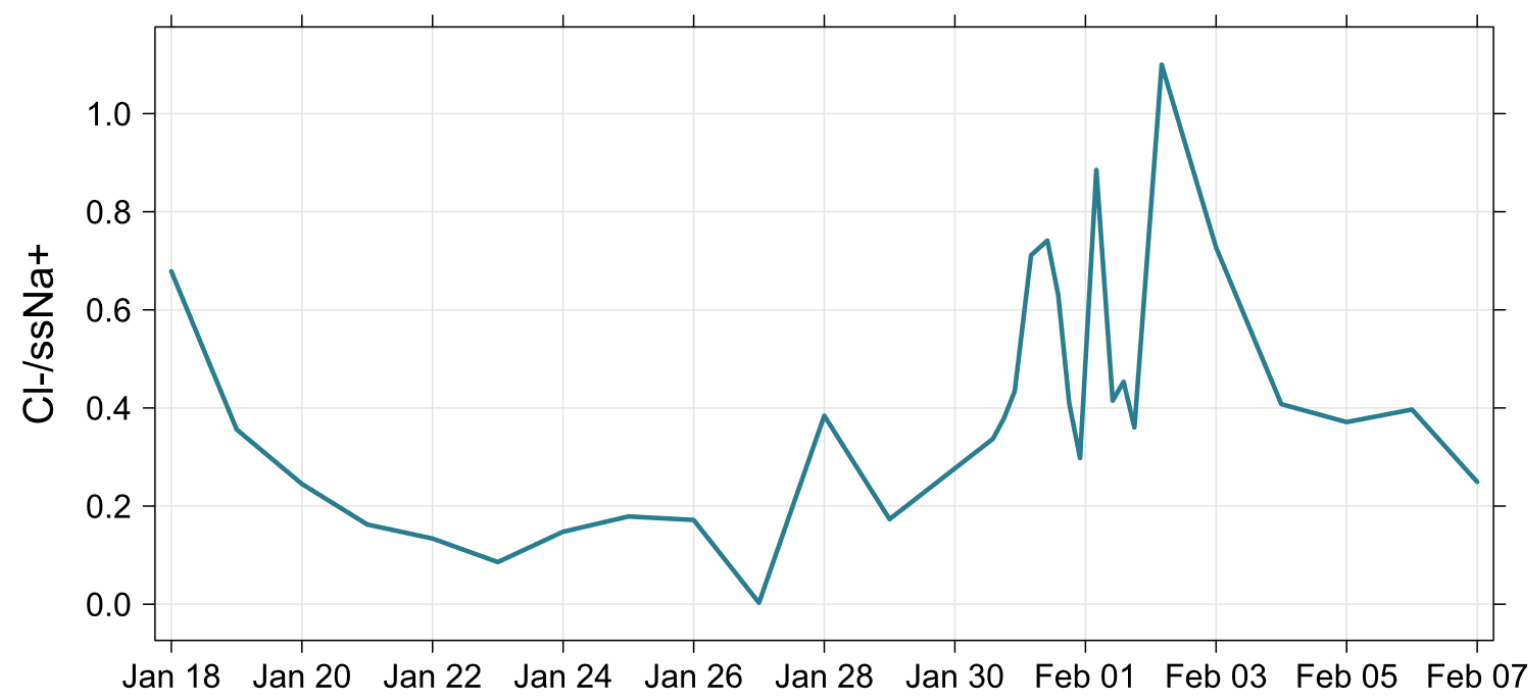

Figure S5: Time series of $\mathrm{Cl}^{-} / s s \mathrm{Na}^{+}$molar ratio during the Bachok measurement campaign. 


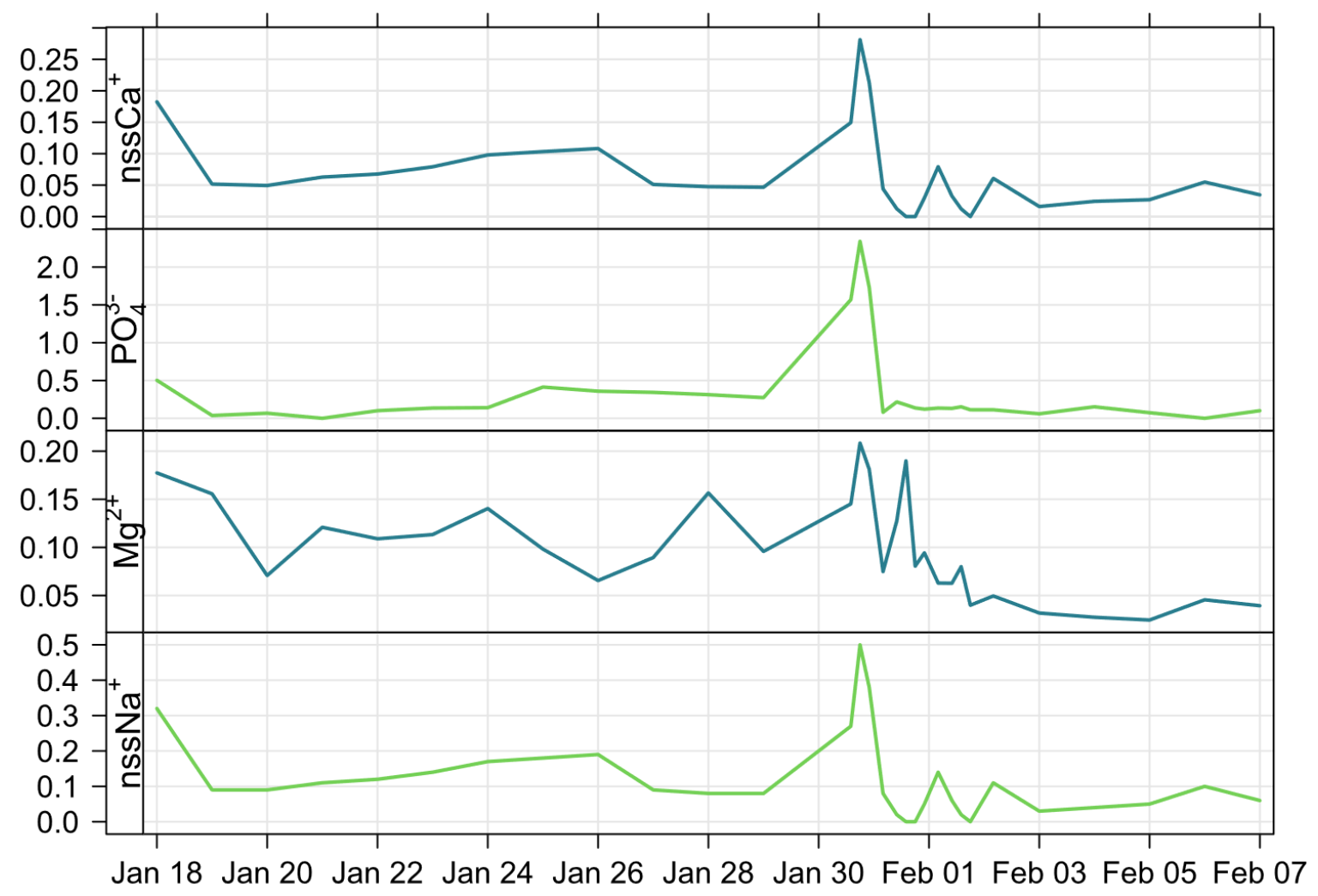

Figure S6: Time series of $n s s \mathrm{Ca}^{2+}, \mathrm{PO}_{4}{ }^{3-}, \mathrm{Mg}^{2+}$ and $n s s \mathrm{Na}^{+}$concentration $\left(\mu \mathrm{g} \mathrm{m}^{-3}\right)$ during the Bachok measurement period (18-01-2014 to 07-02-2014). 


\section{References}

Carslaw, D. C., and Ropkins, K.: openair - An R package for air quality data analysis, Environ Modell Softw, 2728, 52-61, 10.1016/j.envsoft.2011.09.008, 2012.

Carslaw, D. C.: The openair manual - open-source tools for analysing air pollution data. Manual for version 1.14., King's College London, 2015.

Dunmore, R. E., Hopkins, J. R., Lidster, R. T., Mead, M. I., Bandy, B. J., Forster, G., Oram, D. E., Sturges, W. T., Phang, S. M., Abu Samah, A., and Hamilton, J. F.: Development of a Combined Heart-Cut and Comprehensive Two-Dimensional Gas Chromatography System to Extend the Carbon Range of Volatile Organic Compounds Analysis in a Single Instrument, Separations, 3, ARTN 21

10.3390/separations3030021, 2016.

Global Forest Watch: https://www.globalforestwatch.org/, access: 22-11-208, 2018.

Giglio, L., Descloitres, J., Justice, C. O., and Kaufman, Y. J.: An enhanced contextual fire detection algorithm for MODIS, Remote Sens Environ, 87, 273-282, 10.1016/S0034-4257(03)00184-6, 2003. 